\section{Prevention of mental retardation: What do health professionals and general population know about this issue?}

\section{To the Editor:}

As a consequence of advances in genetics, demand for clinical genetic services has increased, reinforcing the need for programs toward the management and prevention of genetic diseases and birth defects. However, literature reports have shown that primary health care professionals (HCPs) and the general population do not have an adequate knowledge level about genetics. $^{1,2}$

Taking into account these issues and considering mental retardation (MR) as a paradigm of clinical genetics, we aimed to explore HCPs' and mothers' knowledge, perceptions and attitudes about genetic and environmental risk factors for this condition.

We carried out a survey with $156 \mathrm{HCPs}$, encompassing 90 physicians (pediatricians, gynecologists-obstetricians, general practitioners and family practitioners), and 66 nurses. All professionals work in the health municipal service of Maringá, a Brazilian town of 303,550 inhabitants with good health indicators for public and private care. In addition, a structural interview was carried out among 100 mothers who live in the same town and were randomly selected based on the official register of born-alive individuals in 2003. Data collection related to the HCPs was carried out from August to December, 2003, and the interviews with the mothers from June to October of the same year. The project was approved by The Ethics Permanent Committee for Researches Involving Human Beings of the State University of Maringa and the informed consent was obtained.

Seventy-five percent of the professionals did not know MR prevalence and 64\% did not know the fraction that can be avoided; a noteworthy percentile were not self-confident enough to inform the patients on phenytoine $(60.3 \%)$, on ethanol $(28.7 \%)$ and on diabetes mellitus (26.2\%) teratogenic effects; $73.9 \%$ are not self-confident in the sense of giving information about the chorionic villus sampling, $58.7 \%$ about the nuchal translucency, and $90 \%$ about the triple test. They also answered not having self-assurance for taking family history and drawing the pedigree (79.4\%). Although they declared that they usually verify the occurrence of MR risk factors, the majority of women interviewed denied this procedure. Considering the mothers' perceptions about risk factors and prevention for mental retardation and/or birth defects, consanguinity, alcohol consumption and rubella were the most commonly mentioned factors $(85 \%, 85 \%, 62 \%$, respectively), while folic acid deficiency, toxoplasmosis and maternal age, $(23 \%, 25 \%, 54 \%$, respectively), were the least mentioned as high risk factors for mental retardation. However, all the mothers had a suitable number of prenatal appointments (an average of 7.7).

The results confirm what have been observed in other studies, ${ }^{3,4}$ and they suggest the necessity of adopting major educational efforts at the primary healthcare level to raise awareness of the risk factors associated with mental retardation. Additionally, further research is necessary in this area, especially to determine the population's appropriate knowledge level for taking informed decision about their health, and to establish a systematic investigation to verify the risk factors prevalence, in order to initiate preventive actions toward the causes of greater impact in the reduction of mental retardation and other abnormalities.

Ana Maria Silveira Machado de Moraes, $M D^{1}$ Luis Alberto Magna, $\mathrm{MD}, \mathrm{PhD}^{2}$

Antônia Paula Marques-de-Faria, MD, $\mathrm{PhD}^{2}$

From the ${ }^{1}$ Departamento de Medicina da Universidade Estadual de Maringá, Paraná, Brasil; ${ }^{2}$ Departamento de Genética Médica da Faculdade de Ciências Médicas da Universidade Estadual de Campinas, São Paulo, Brasil

\section{References}

1. Emery J, Watson E, Rose P, Andermann A. A systematic review of the literature exploring the role of primary care in genetic services. Fam Pract 1999;16:426-445.

2. Henneman L, Timmermans DRM, van der Wal G. Public experience, knowledge and expectations about medical genetics and the use of genetic information. Community Genet 2004;7:33-43.

3. Summerton N, Garrood PVA. The family history in family practice: a questionnaire study. Fam Pract 1997;14:285-288.

4. Garcias GL, Schüler-Faccini L. The beliefs of mothers in sourthen Brazil regarding risk-factors associated with congenital abnormalities. Genet Mol Biol 2004;27: 147-153. 